\title{
PREVALENCE OF HYPERTENSION AMONG ADULT POPULATION IN SLUMS OF WEST DELHI
}

\section{SUPRIYA DWIVEDI ${ }^{1,2}$, ZAOZIANLUNGLIU GONMEI ${ }^{1,3}$, GURUDAYAL SINGH TOTEJA ${ }^{1,4 *}$, NIDHI SRIVASTAVA ${ }^{2}$, NAVAL KISHORE VIKRAM ${ }^{5}$, SPRIHA RAO ${ }^{1}$, CHETRAM MEENA ${ }^{4}$}

\begin{abstract}
${ }^{1}$ Division of Nutrition, Centre for Promotion of Nutrition Research and Training with special focus on North East, Tribal and Inaccessible population (Indian Council of Medical Research), New Delhi, India. ${ }^{2}$ Department of Biotechnology, Amity Institute of Biotechnology, Amity University Uttar Pradesh, Noida, Uttar Pradesh, India. ${ }^{3}$ Department of Nutrition, Amity Institute of Food Technology, Amity University Uttar Pradesh, Noida, Uttar Pradesh, India. ${ }^{4}$ Department of Nutrition, Desert Medicine Research Centre (Indian Council of Medical Research), Jodhpur, Rajasthan, India. ${ }^{5}$ Department of Medicine, All India Institute of Medical Sciences, New Delhi, India. Email: gstoteja@gmail.com
\end{abstract}

Received: 17 June 2017, Revised and Accepted: 16 September 2017

\section{ABSTRACT}

Objective: The present study was conducted to assess the prevalence of hypertension in adult population residing in slums of West Delhi.

Methods: A cross-sectional study was conducted among adult population of 18-59 years residing in urban slums of West Delhi. Blood pressure was measured using digital machine (OMRON). The data obtained were analyzed for percent prevalence, mean, standard deviation, and median. Joint National Committee (JNC)on prevention, detection, evaluation, and treatment of high blood pressure (JNC)VI and JNC VII criteria were used to classify hypertension.

Results: The overall prevalence of hypertension was $25.3 \%$. The prevalence was higher (27.9\%)in males than females (22.8\%)and also in the age group 46-59 years (43.0\%)as compared to 18-45 years (19.8\%). The overall prevalence of prehypertension, Stage I and Stage II hypertension, respectively, was $35.2 \%, 16.1 \%$ and $9.2 \%$.

Conclusion: A one-fourth of the adult population is hypertensive. Early diagnosis and treatment are advisable, besides awareness about dietary and lifestyle modification.

Keywords: Joint National Committee VII, Prehypertension, Hypertension.

(C) 2017 The Authors. Published by Innovare Academic Sciences Pvt Ltd. This is an open access article under the CC BY license (http://creativecommons. org/licenses/by/4. 0/) DOI: http://dx.doi.org/10.22159/ajpcr.2017.v10i12.20802

\section{INTRODUCTION}

Raised blood pressure is one of the leading risk factors for global mortality and is estimated to have caused 9.4 million deaths and $7 \%$ of disease burden in 2010 [1]. It also leads to economic burden among low socioeconomic population [2]. Early diagnosis of hypertension is needed to prevent associated microvascular and macrovascular morbidity and mortality [3]. A systematic review and meta-analysis carried out revealed that the overall prevalence of hypertension in India as $29.8 \%$ [4]. In a study carried out by Indian Council of Medical Research in 1994 using a stratified multistage sampling design, in three states (Tamil Nadu, Maharashtra, and Jharkhand)and one union territory (Chandigarh)of India covering 14059 populations, prevalence of hypertension was observed as $26.3 \%$ [5]. Studies carried out in slums have also reported the prevalence of hypertension as high as 14 to $26 \%$ [6-8]. The present study was conduced to assess the prevalence of hypertension in adult population residing in slums of West Delhi.

\section{METHODS}

The cross-sectional study was conducted in adult population residing in urban slums of west Delhi to assess the prevalence of hypertension. A total of 423 male and female adults aged 18-59 years were recruited. The study population belonged to low socioeconomic background and are mainly migrants from neighboring states such as Uttar Pradesh and Bihar. Institutional Ethical clearance was obtained, and informed consent was also obtained from all the study volunteers. Blood pressure was measured twice using digital machine (OMRON)after an interval of 5 minutes and mean value was taken. Joint National Committee (JNC)VII criteria were used to define hypertension and its various categories [9].
As per JNC VI criteria, blood pressure of higher category was used to classify hypertension in case systolic, and diastolic blood pressure falls into different categories [10]. The data obtained were analyzed for percent prevalence, mean, standard deviation, and median.

\section{RESULTS}

Among 423 adults recruited, 204 (48.2\%)and 219 (51.7\%)were males and females, respectively, and 323 (76.4\%)and 100 (23.6\%), respectively, were in the age group 18-45 and $46-59$ years.

The overall prevalence of hypertension was $25.3 \%$ (Table 1). The prevalence was higher (27.9\%) in males than females (22.8\%)and also in the age group 46-59 years (43.0\%)as compared to years $(19.8 \%)$. The prevalence of Stage I and Stage II hypertension, respectively, was $16.1 \%$ and $9.2 \%$. The prevalence of Stage I hypertension was around $16 \%$ in both male and female, whereas in the age group of 46-59 years, the prevalence was higher $(31.7 \%)$ in female than male $(20.3 \%)$. The prevalence of Stage II hypertension was more (11.8\%)in male than female $(6.8 \%)$. Furthermore, in the age group of $18-45$ years, the prevalence of Stage II hypertension was more (7.6\%)in male than female $(5.6 \%)$, whereas, in the age group $46-59$ years, it was more $(22.0 \%)$ in male than female $(12.2 \%)$.

The mean systolic and diastolic blood pressure of the population covered $(n=423)$ was $126.4 \pm 19.2$ and $79.2 \pm 11.5 \mathrm{mmHg}$, respectively (Table 2). The mean systolic blood pressure of hypertensive subjects was $151.3 \pm 15.9 \mathrm{mmHg}$ whereas of non-hypertensive it was $118.0 \pm 11.3 \mathrm{mmHg}$. Similarly, the mean diastolic blood pressure of hypertensive subjects was $92.3 \pm 10.2 \mathrm{mmHg}$ whereas of nonhypertensive it was $74.8 \pm 7.9 \mathrm{mmHg}$. 
The median systolic and diastolic blood pressure of the population covered ( $\mathrm{n}=423)$ was 123.5 and $78.0 \mathrm{mmHg}$, respectively (Table 3). The median systolic blood pressure of hypertensive subjects was 148.0 whereas it was $119.0 \mathrm{mmHg}$ among non-hypertensive. Similarly, the median diastolic blood pressure of hypertensive subjects was $91.5 \mathrm{mmHg}$ whereas among non-hypertensive it was $75.3 \mathrm{mmHg}$.

\section{DISCUSSION}

The overall prevalence of hypertension was $25.3 \%$. Studies carried out in different parts of the country have also reported the prevalence of hypertension around $20 \%$. A study carried out in an urban slum of Mumbai reported the prevalence of hypertension among $\geq 18$ years population ( $\mathrm{n}=1089$ ) as $23.59 \%$ [11]. Similarly, a community-based study conducted by in 2016 in south India among urban and rural population covering 600 adults showed an overall prevalence of hypertension as $21.0 \%$ with $23.7 \%$ and $18.3 \%$ in urban and rural population, respectively [12]. A study carried out in 2016 among 556 rural adult population of central India also reported the overall prevalence of hypertension as $21.6 \%$ [13]. A cross-sectional study conducted among 310 residents (aged 20-59 years)of a slum resettlement colony in Delhi reported the overall prevalence of hypertension as $17.4 \%$ [14].

However, as per National Family Health Survey (NFHS) 4 carried out during 2015-16 by Ministry of Health and Family Welfare, Government of India, the prevalence of hypertension in the country was reported as $13.6 \%$ and $10.8 \%$ among men and women aged $15-45$ years of age, respectively [15]. With respect to National Capital Territory of Delhi, the prevalence of hypertension was reported to be $4.2 \%$ and $7.6 \%$ among men and women aged 15-45 years of age, respectively [16]. Our

Table 1: Prevalence of hypertension among adults $(n=423)$

\begin{tabular}{|c|c|c|c|c|c|c|c|c|c|}
\hline \multirow[t]{3}{*}{ Category } & \multicolumn{3}{|c|}{ All (years) } & \multicolumn{3}{|c|}{ Male (years) } & \multicolumn{3}{|c|}{ Female (years) } \\
\hline & $18-59$ & $18-45$ & $46-59$ & 18-59 & $18-45$ & 46-59 & $18-59$ & $18-45$ & $46-59$ \\
\hline & $\mathrm{N}=423$ & $\mathrm{~N}=323$ & $\mathrm{~N}=100$ & $\mathrm{~N}=204$ & $\mathrm{~N}=145$ & $N=59$ & $\mathrm{~N}=\mathbf{2 1 9}$ & $\mathrm{N}=178$ & $\mathrm{~N}=41$ \\
\hline $\begin{array}{l}\text { Pre-hypertensive } \\
\text { (120-139 or } 80-89 \text { ) }\end{array}$ & $\begin{array}{l}149 \\
(35.2)\end{array}$ & $\begin{array}{l}119 \\
(36.8)\end{array}$ & $\begin{array}{l}30 \\
(30.0)\end{array}$ & $\begin{array}{l}90 \\
(44.1)\end{array}$ & $\begin{array}{l}76 \\
(52.4)\end{array}$ & $\begin{array}{l}14 \\
(23.7)\end{array}$ & $\begin{array}{l}59 \\
(26.9)\end{array}$ & $\begin{array}{l}43 \\
(24.2)\end{array}$ & $\begin{array}{l}16 \\
(39.0)\end{array}$ \\
\hline Hypertensive & 107 & 64 & 43 & 57 & 32 & 25 & 50 & 32 & 18 \\
\hline$(\geq 140$ or $\geq 90)$ & $(25.3)$ & (19.8) & $(43.0)$ & $(27.9)$ & $(22.1)$ & $(42.4)$ & $(22.8)$ & $(18.0)$ & $(43.9)$ \\
\hline Stage I hypertension & 68 & 43 & 25 & 33 & 21 & 12 & 35 & 22 & 13 \\
\hline$(140-159$ or $90-99)$ & $(16.1)$ & $(13.3)$ & $(25.0)$ & $(16.2)$ & $(14.5)$ & $(20.3)$ & $(16.0)$ & $(12.4)$ & (31.7) \\
\hline Stage II hypertension & 39 & 21 & 18 & 24 & 11 & 13 & 15 & 10 & 5 \\
\hline$(\geq 160$ or $\geq 100)$ & $(9.2)$ & (6.5) & $(18.0)$ & (11.8) & (7.6) & $(22.0)$ & $(6.8)$ & (5.6) & $(12.2)$ \\
\hline
\end{tabular}

Values entered in parenthesis is percent prevalence

Table 2: Distribution of mean systolic and diastolic blood pressure $(n=423)$

\begin{tabular}{|c|c|c|c|c|c|c|}
\hline \multirow[t]{2}{*}{ Category } & \multicolumn{2}{|l|}{ Male } & \multicolumn{2}{|l|}{ Female } & \multicolumn{2}{|l|}{ All } \\
\hline & $\begin{array}{l}\text { Systolic } \\
\text { BP (mmHg) }\end{array}$ & $\begin{array}{l}\text { Diastolic } \\
\text { BP (mmHg) }\end{array}$ & $\begin{array}{l}\text { Systolic } \\
\text { BP (mmHg) }\end{array}$ & $\begin{array}{l}\text { Diastolic } \\
\text { BP (mmHg) }\end{array}$ & $\begin{array}{l}\text { Systolic } \\
\text { BP (mmHg) }\end{array}$ & $\begin{array}{l}\text { Diastolic } \\
\text { BP (mmHg) }\end{array}$ \\
\hline \multicolumn{7}{|c|}{ Age groups (18-59 years) } \\
\hline Hypertensive & $153.0 \pm 17.6$ & $94.6 \pm 10.2$ & $146.6 \pm 13.8$ & $89.8 \pm 9.7$ & $151.3 \pm 15.9$ & $92.3 \pm 10.2$ \\
\hline Non-hypertensive & $121.3 \pm 9.3$ & $75.5 \pm 8.1$ & $115.2 \pm 12.1$ & $74.2 \pm 7.8$ & $118.0 \pm 11.3$ & $74.8 \pm 7.9$ \\
\hline Total & $130.1 \pm 18.7$ & $80.8 \pm 12.2$ & $123.0 \pm 19.1$ & $77.8 \pm 10.5$ & $126.4 \pm 19.2$ & $79.2 \pm 11.5$ \\
\hline \multicolumn{7}{|c|}{ Age groups (18-45 years) } \\
\hline Hypertensive & $149.1 \pm 15.2$ & $94.3 \pm 8.8$ & $149.1 \pm 15.2$ & $91.1 \pm 11.4$ & $149.6 \pm 14.6$ & $92.7 \pm 10.2$ \\
\hline Non-hypertensive & $122.0 \pm 9.0$ & $75.7 \pm 8.1$ & $113.3 \pm 11.7$ & $73.7 \pm 7.8$ & $117.3 \pm 11.4$ & $74.6 \pm 8.0$ \\
\hline Total & $127.7 \pm 15.5$ & $75.1 \pm 11.3$ & $120.0 \pm 18.3$ & $76.8 \pm 10.9$ & $123.5 \pm 17.5$ & $78.2 \pm 11.1$ \\
\hline \multicolumn{7}{|c|}{ Age groups (46-59 years) } \\
\hline Hypertensive & $157.9 \pm 19.6$ & $94.9 \pm 11.9$ & $150.4 \pm 13.3$ & $87.5 \pm 5.3$ & $154.8 \pm 17.5$ & $91.8 \pm 10.3$ \\
\hline Non-hypertensive & $118.8 \pm 9.9$ & $74.6 \pm 8.2$ & $125.2 \pm 9.6$ & $77.7 \pm 9.6$ & $121.4 \pm 10.2$ & $75.8 \pm 7.7$ \\
\hline Total & $135.4 \pm 24.4$ & $83.2 \pm 14.1$ & $136.3 \pm 16.9$ & $82.0 \pm 7.5$ & $135.7 \pm 21.5$ & $82.7 \pm 11.9$ \\
\hline
\end{tabular}

Table 3: Distribution of median systolic and diastolic blood pressure $(n=423)$

\begin{tabular}{|c|c|c|c|c|c|c|}
\hline \multirow[t]{2}{*}{ Category } & \multicolumn{2}{|l|}{ Male } & \multicolumn{2}{|l|}{ Female } & \multicolumn{2}{|l|}{ All } \\
\hline & $\begin{array}{l}\text { Systolic } \\
\text { BP (mmHg) }\end{array}$ & $\begin{array}{l}\text { Diastolic } \\
\text { BP (mmHg) }\end{array}$ & $\begin{array}{l}\text { Systolic } \\
\text { BP (mmHg) }\end{array}$ & $\begin{array}{l}\text { Diastolic } \\
\text { BP (mmHg) }\end{array}$ & $\begin{array}{l}\text { Systolic } \\
\text { BP (mmHg) }\end{array}$ & $\begin{array}{l}\text { Diastolic } \\
\text { BP (mmHg) }\end{array}$ \\
\hline \multicolumn{7}{|c|}{ Age groups (18-59 years) } \\
\hline Hypertensive & 149.5 & 93.0 & 146.8 & 90.0 & 148.0 & 91.5 \\
\hline Non-hypertensive & 122.5 & 76.0 & 115.0 & 74.0 & 119.0 & 75.3 \\
\hline Total & 126.5 & 79.0 & 119.5 & 77.0 & 123.5 & 78.0 \\
\hline \multicolumn{7}{|c|}{ Age groups (18-45 years) } \\
\hline Hypertensive & 148.0 & 92.5 & 146.8 & 90.8 & 147.5 & 91.5 \\
\hline Non-hypertensive & 123.0 & 76.5 & 113.7 & 74.0 & 119.0 & 75.0 \\
\hline Total & 126.0 & 79.0 & 117.0 & 75.5 & 122.0 & 77.0 \\
\hline \multicolumn{7}{|c|}{ Age groups (46-59 years) } \\
\hline Hypertensive & 153.5 & 94.0 & 146.8 & 89.8 & 151.5 & 91.0 \\
\hline Non-hypertensive & 117.8 & 75.3 & 125.0 & 77.5 & 119.5 & 75.5 \\
\hline Total & 131.5 & 82.5 & 135.0 & 83.0 & 132.8 & 82.8 \\
\hline
\end{tabular}


findings indicated a higher prevalence of hypertension compared to the NFHS findings as the age group covered was different, and our study indicated higher prevalence among the age group of 46-59 years.

Our study indicated higher prevalence (27.9\%)among males than females (22.8\%). A study conducted in 2015 on 957 adult populations residing in an urban locality also indicated that hypertension was more prevalent among males compared to females as men have more associated risk factors such as smoking, alcohol, and stress [6].

Age plays an important role in the development of hypertension [17]. We observed a higher prevalence of hypertension among 46-59 years of age (43.0\%)as compared to 18-45 years of age (19.8\%). A study carried out among 1154 adult populations in a municipal town of Kerala reported the prevalence of hypertension as $32.3 \%$ and also indicated that the prevalence increases with age [18]. A study carried out among 10,175 adults aged $\geq 20$ years in slums of Kolkata reported the prevalence of hypertension as $42 \%$ and prevalence was higher in men, above 60 years age, in minority community, in those with a higher household income, and among tobacco users [19]. An epidemiological study carried out among 3629 adults between younger and older two age groups in western Indian population showed that hypertension prevalence differs in two different age groups $11 \%$ in younger ( $\leq 40$ years)and $40 \%$ in older age groups ( $>40$ years) [20].

The prevalence of prehypertension was $35.2 \%$. Similarly, a study carried out among adults in slums also reported the prevalence of prehypertension as 35\% [14]. Another study carried out among the rural adult population of central India indicated the prevalence of prehypertension as $32.2 \%$ [13].

\section{CONCLUSION}

A one-fourth, of the adult population in slums, is hypertensive. Early diagnosis and treatment are advisable, besides awareness about dietary and lifestyle modification.

\section{REFERENCES}

1. World Health Organization (WHO). Global Status Report on Noncommunicable diseases. Geneva: World Health Organization; 2014

2. Nachiya RA, Parimalakrishnan S, Rao MR. Cost analysis of antihypertensive agents in rural population: A prospective study. Int J Pharm Pharm Sci 2016;8(3):225-30.

3. Swami SS, Swami SC, Patil VW, Kanhere AM. Hypertension and diabetes in India: A review. Int J Clin Biochem Res 2015;2(1):54-8

4. Anchala R, Kannuri NK, Pant H, Khan H, Franco OH, Di Angelantonio E, et al. Hypertension in India: A systematic review and meta-analysis of prevalence, awareness, and control of hypertension. J Hypertens 2014;32(6):1170-7.
5. Bhansali A, Dhandania VK, Deepa M, Anjana RM, Joshi SR, Joshi PP, et al. Prevalence of and risk factors for hypertension in urban and rural India: The ICMR-INDIAB study. J Hum Hypertens 2015;29(3):204-9.

6. Ahmad S. Prevalence and risk factors of hypertension, among adults residing in an urban area of North India. Int J Pure Appl Biosci 2015;3(2):338-44

7. Bendhari ML, Karode RS, Haralkar SJ. Study of prevalence and risk factors of hypertension in adults in an urban slum area of Western Maharashtra, India. Int J Community Med Public Health 2016;3(10):2812-6

8. Das OP, Naik VA, Narasannavar AB, Sah RK. Prevalence of hypertension among adults residing in urban slums of Ramnagar, Belgaum City-A Cross-Sectional Study. IOSR J Dent Med Sci 2014;13(5):102-4

9. National Institutes of Health. The Seventh Report of the Joint National Committee on Prevention, Detection, Evaluation, and Treatment of High Blood Pressure. USA: National Institutes of Health; 2004.

10. National Institutes of Health. The Sixth Report of the Joint National Committee on Prevention, Detection, Evaluation, and Treatment of High Blood Pressure. USA: National Institutes of Health; 1997.

11. Dhikale PT, Solanki MJ, Shrivastava SR. A study of epidemiology of hypertension in an urban slum community of Mumbai. Biol Med 2015;S3:3

12. Ismail IM, Kulkarni AG, Meundi AD, Amruth M. A community-based comparative study of prevalence and risk factors of hypertension among urban and rural populations in a coastal town of South India. Sifa Med J 2016;3:41-7.

13. Premkumar R, Pothen J, Rima J, Arole S. Prevalence of hypertension and prehypertension in a community-based primary health care program villages at central India. Indian Heart J 2016;68(3):270-7.

14. Panesar S, Chaturvedi S, Saini NK, Avasthi R, Singh A. Prevalence and predictors of hypertension among residents aged 20-59 years of a slum-resettlement colony in Delhi, India. WHO South East Asia J Public Health 2013;2(2):83-7.

15. National Family Health Survey-4 (2015-2016), India Factsheet. Available from: http://rchiips.org/NFHS/factsheet_NFHS-4.shtml. [Last accessed on 2017 Apr 26].

16. National Family Health Survey-4 (2015-2016), State Factsheet. NCT Delhi. Available from: http://rchiips.org/NFHS/pdf/NFHS4/DL FactSheet.pdf. [Last accessed on 2017 Apr 26].

17. Venkataraman R, Satish Kumar BP, Kumaraswamy M, Singh R, Pandey M, Tripathi P, et al. Smoking, alcohol and hypertension. Int J Pharm Pharm Sci 2013;5(4):28-32.

18. Sebastian NM, Jesha MM, Haveri SP, Nath AS. Hypertension in Kerala: A study of prevalence, control, and knowledge among adults. Int J Med Sci Public Health 2016;5(10):2041-6.

19. Banerjee S, Mukherjee TK, Basu S. Prevalence, awareness, and control of hypertension in the slums of Kolkata. Indian Heart $\mathbf{J}$ 2016;68(3):286-94.

20. Shukla AN, Madan T, Thakkar BM, Parmar MM, Shah KH. Prevalence and predictors of undiagnosed hypertension in an apparently healthy western Indian population. Adv Epidemiol 2015;2015: Article ID:649184, 5 . 